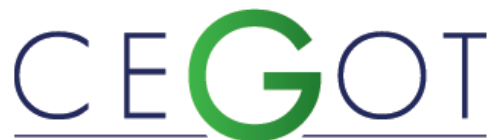

Centro de Estudos de Geografia e Ordenamento do Território
Geografia e Ordenamento do Território, Revista Eletrónica Centro de Estudos de Geografia e Ordenamento do Território http://cegot.org ISSN: 2182-1267
VERGARA, FERNÁN

Universidade Federal do Tocantins

77001-090. 109 Norte, Av. NS 15, Plano Diretor Norte, Palmas/TO, Brasil vergara@uft.edu.br

Chiesa, Viviane

Universidade Federal do Tocantins

77001-090. 109 Norte, Av. NS 15, Plano Diretor Norte, Palmas/TO, Brasil vivichiesa@yahoo.com.br

\section{COSTA, CECILIA}

Universidade Federal do Tocantins

77001-090. 109 Norte, Av. NS 15, Plano Diretor Norte, Palmas/TO, Brasil camc.miranda@gmail.com

\section{Oliveira, Roberta}

Universidade Federal do Tocantins

77001-090. 109 Norte, Av. NS 15, Plano Diretor Norte, Palmas/TO, Brasil robertaoliveira@uft.edu.br

\section{DIAS, RICARDO}

Universidade Federal do Tocantins

77001-090. 109 Norte, Av. NS 15, Plano Diretor Norte, Palmas/TO, Brasil ricdias@uft.edu.br

MACIEL, GIRLENE

Universidade Federal do Tocantins

77001-090. 109 Norte, Av. NS 15, Plano Diretor Norte, Palmas/TO, Brasil maciel@uft.edu.br

\title{
Aplicabilidade do modelo matemático SAD-IPH na análise de processos de outorga: o caso da Bacia do Ribeirão Taquaruçu
}

The SAD-IPH mathematical model applicability in concession processes analysis: the Taquaruçu Stream's Catchment case

Referência: Vergara, Fernán; Chiesa, Viviane; Costa, Cecilia; Oliveira, Roberta; Dias, Ricardo; Maciel, Girlene (2021). Aplicabilidade do modelo matemático SAD-IPH na análise de processos de outorga: o caso da Bacia do Ribeirão Taquaruçu. Revista de Geografia e Ordenamento do Território (GOT), n.o 21 (Junho). Centro de Estudos de Geografia e Ordenamento do Território, p. 208-234, dx.doi.org/ 10.17127/got/2021.21.009

\section{RESUMO}

Para que uma outorga de direito de uso da água seja emitida é preciso aferir se o corpo hídrico possui capacidade para atender a demanda solicitada para a captação de água, considerando os usos existentes e a hidrologia local. Nesse contexto, este trabalho teve como objetivo avaliar a aplicabilidade do modelo matemático SAD-IPH para simular cenários de demanda de água na Bacia Hidrográfica do Ribeirão Taquaruçu Grande, localizada em Palmas - TO. As simulações demonstraram que a bacia já apresenta trechos em situação crítica quanto à disponibilidade, que é agravada nos meses de seca e com o passar dos anos. 
Dessa forma, fica evidente que a Companhia de Saneamento deve buscar novas alternativas para suprir a demanda de seus usuários, principalmente nos meses de seca da região. Conclui-se, portanto, que a ferramenta utilizada é adequada para subsidiar o órgão gestor e o comitê de bacia na tomada de decisões quanto à análise de outorgas, visto que possibilita - acesso a dados antes não disponíveis, incidindo assim, em menos erros nesse procedimento. Também, como medida de segurança hídrica, é fundamental que a preservação da bacia seja feita de forma urgente e intensa, já que, além do aumento da demanda por água, há o risco de a disponibilidade hídrica ficar comprometida por uso e ocupação mais intenso, principalmente nas regiões de proteção de mananciais.

Palavras-chave: modelo matemático, recursos hídricos, outorga de uso da água, cenários.

\begin{abstract}
In order to issue a water permit, which allows abstraction of water in a given place, the issuer needs to make sure, based on the hydrology of the region, that the amount of water available in the water body is sufficient to meet not only the demand associated with the required entitlement, but also all the existing demands from other users in the basin. This paper aims at evaluating the usefulness of the SAD-IPH mathematical model to simulate water demand scenarios in the Ribeirão Taquaruçu basin, located in the city of Palmas, state of Tocantins. Simulations provided by the SAD-IPH model indicate that the balance between water availability and demand is already critical in some parts of the basin, especially during the dry season, and the situation worsens over time. These results clearly suggest the local water utility needs to search for new water sources to meet the growing demand, mainly during the dry season. Results show the mathematical tool used in the analysis provides new and valuable information to decision makers (water resources institutions and river basin committees), potentially reducing the risk of making bad decisions. Additionally, as a water security measure, it is crucial to enforce the preservation of sensitive areas in the watershed because there is already an intense occupation in preserved areas next to water sources, a process that is likely to result in water yield reduction, which combined with an increase in the water demand over time, will compromise water security.
\end{abstract}

Keywords: mathematical model, water resources, water permit, scenarios.

\title{
1. Introdução
}

A gestão de recursos hídricos tem avançado nas últimas décadas no Brasil, principalmente após a publicação da Política Nacional de Recursos Hídricos - PNRH (Lei Federal no 9433/97), que apresenta o desenvolvimento sustentável regional como seu objetivo central, adotando a bacia hidrográfica como recorte geográfico para a sua implementação; além de estabelecer uma série de instrumentos de gestão dos recursos hídricos que visam, entre outros, "assegurar à atual e às futuras gerações a necessária disponibilidade de água em padrões de qualidade adequados aos respectivos usos" - Art. 2, Inciso I (BRASIL, 1997). Um 
desses instrumentos de gestão dos Recursos Hídricos é a Outorga de Direito de Uso dos Recursos Hídricos, que consiste em uma autorização concedida pelo poder público, a qual faculta ao outorgado o direito de uso da água, por prazo determinado, nos termos e nas condições expressas no respectivo ato administrativo (FARIAS, 2008).

No Estado do Tocantins, a legislação referente à outorga foi aprovada em 22 de março de 2002, de acordo com a Lei Estadual no 1.307. Todavia, o instrumento de outorga somente começou a ser implantado no ano de 2005, quando foi publicado o Decreto Regulamentador $n^{\circ} 2.432$, de 06 de junho de 2005. O referido decreto determinou que 0 órgão responsável pela análise e emissão das outorgas nas áreas de abrangência do Estado, é o Instituto Natureza do Tocantins - NATURATINS. Entretanto, a implementação desse instrumento ainda apresenta uma série de deficiências que necessitam ser mitigadas para que a outorga cumpra, de maneira adequada, seu papel.

Para uma gestão efetiva dos recursos hídricos é imprescindível a utilização de bases de dados confiáveis. No entanto, geralmente são insuficientes ou não existem. Nesse caso, uma alternativa é a aplicação de modelos matemáticos que possam estimar o comportamento hidrológico de uma bacia hidrográfica, possibilitando assim, a análise de alternativas que auxiliem na tomada de decisões, minimizando as incertezas das análises das outorgas pelo órgão gestor (CASTRO, 2013).

Nessa conjuntura, emergem a importância e a utilidade dos Sistemas de Apoio à Decisão SAD. Os SAD nada mais são que sistemas computacionais instituídos por bases de dados e modelos matemáticos que, interagindo entre si, por meio de uma interface gráfica, apoia indivíduos que tomam decisões no processo de busca, análise e seleção de alternativas para solução de seus problemas não estruturados (ou parcialmente estruturados). Problemas não estruturados são aqueles para os quais não há soluções por algoritmos definidos, e em função disso não são facilmente tratáveis por computador. Dessa forma, a solução desses problemas requer uma estreita interação entre homem e máquina, sendo essa uma das principais características de um SAD (PORTO e AZEVEDO, 1997).

Azevedo et al. (2003) enfatizam que a utilização prática de Sistemas de Suporte à Decisão SSD para outorga, no Brasil, ainda é limitada. Todavia, três sistemas têm sido aplicados no Brasil, são eles: o Sistema de Controle de Balanço Hídrico para a Bacia do Rio São Francisco, 
proposto por Collischonn e Lopes (2008) e utilizado pela ANA, o qual vem sendo aplicado com sucesso em outras bacias como a do rio Paraná e rio Grande (COLLISCHONN e LOPES, 2009); o "SSD RB" - Sistema de Suporte à Decisão para a Gestão Quali-Quantitativa dos Processos de Outorga e Cobrança pelo uso da Água desenvolvido por Rodrigues (2005), como Tese de Doutorado na USP, que tem sido usado nas bacias dos rios Jundiaí e Paraíba do Sul e; o "SAD-IPH" - Sistema de Apoio à Decisão para gerenciamento de bacias hidrográficas, desenvolvido pelo Instituto de Pesquisas Hidráulicas da Universidade Federal do Rio Grande do Sul.

A grande vantagem do SAD-IPH com relação aos SAD existentes constitui-se no fato do mesmo poder se conectar diretamente a um banco de dados geoespacial, podendo ser flexível para qualquer bacia hidrográfica (RIO GRANDE DO SUL, 2011). O SAD-IPH é um sistema de suporte à decisão voltado à gestão do uso dos recursos hídricos e aplicável aos instrumentos da Política Nacional dos Recursos Hídricos, que permite realizar balanços hídricos quantitativos e simulações da qualidade da água em regime permanente de vazões e lançamentos de efluentes em modo contínuo (MEDEIROS, 2014). Esse modelo possui interface com aplicativos de Sistemas de Informações Geográficas (GIS), o que possibilita melhor organização e definição dos dados de entrada por meio de um banco de dados, a elaboração e edição de cenários ambientais e sua representação em forma de gráficos e mapas, controle e simulações, além de extrair e organizar as saídas do modelo (MEIRA NETO et al., 2011).

Dentro desse contexto, este trabalho tem como objetivo avaliar a aplicabilidade do modelo SAD-IPH para quantificar o balanço hídrico entre a demanda e oferta da água da Bacia Hidrográfica do Ribeirão Taquaruçu Grande, para diferentes cenários de demanda, de forma a subsidiar o órgão gestor dos recursos hídricos e o comitê de bacia na tomada de decisões quanto à análise para a emissão de outorgas de captação de água.

\section{2. Área de Estudo}

A bacia hidrográfica do Ribeirão Taquaruçu, localiza-se na parte centro-sul do município de Palmas, entre os paralelos $10^{\circ} 10^{\prime} 41^{\prime \prime}$ e $10^{\circ} 25^{\prime} 05^{\prime \prime}$ de latitude Sul e os meridianos $48^{\circ} 03^{\prime} 46^{\prime \prime}$ 
e $48^{\circ} 18^{\prime} 34^{\prime \prime}$ de longitude Oeste de Greenwich, apresenta $461,39 \mathrm{~km}^{2}$ de área, se estendendo por 29,2 km, como se observa na Figura 1.

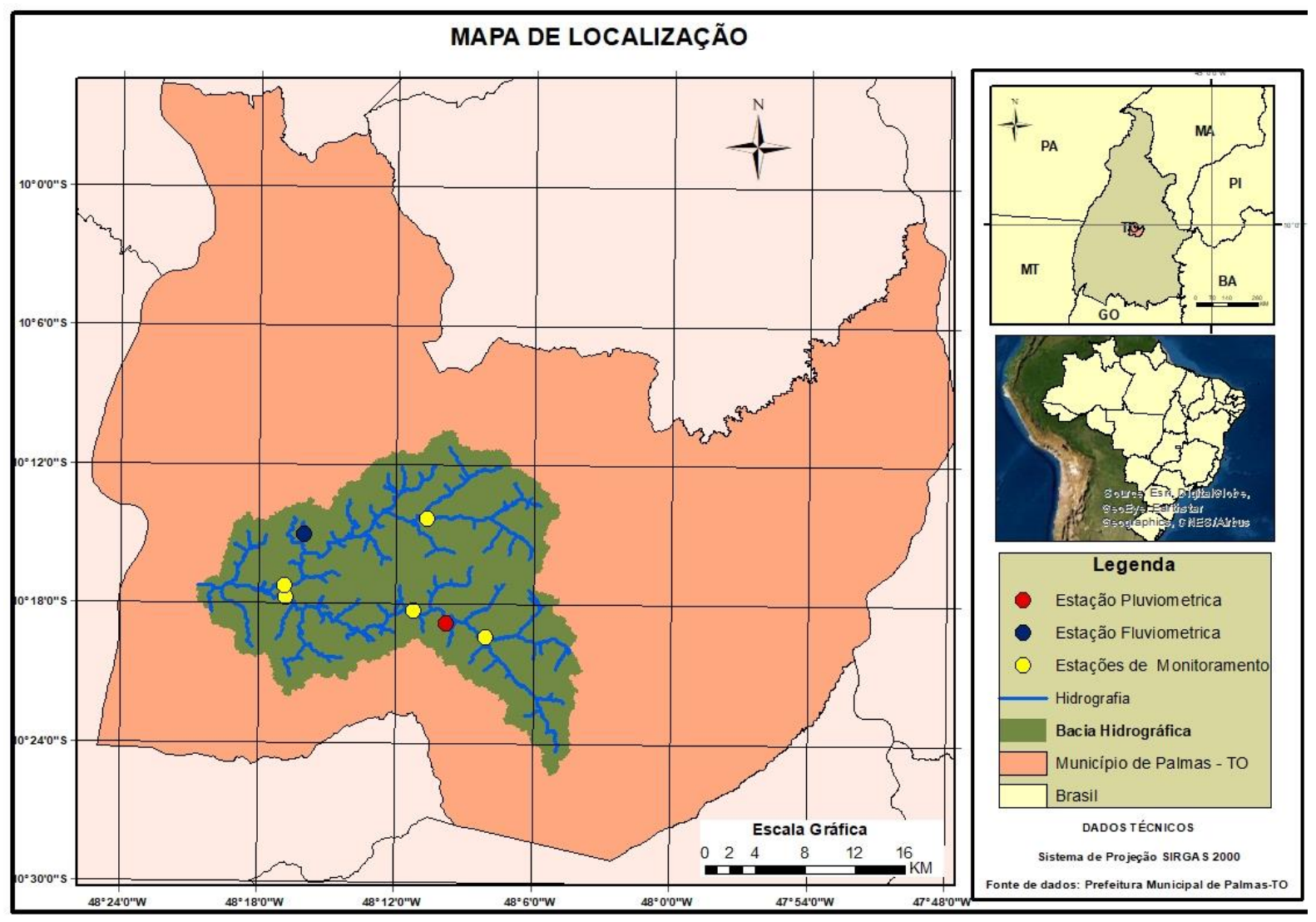

Figura 1. Mapa da localização da bacia hidrográfica do ribeirão Taquaruçu Grande, Palmas - TO.

A nascente do Ribeirão Taquaruçu está situada na Serra do Lajeado, onde ocorrem diversas cascatas e balneários de interesse para o ecoturismo, e sua jusante dá-se no reservatório da UHE Luís Eduardo Magalhães, junto à área urbana de Palmas (BARROS et al., 2011).

Essa bacia hidrográfica é afluente direta do Rio Tocantins e seus principais contribuintes pela margem esquerda são o Ribeirão Taquaruçuzinho, o Córrego Machado e o Córrego Buritizal e pela margem direita são os Córregos Macacão e Tiúba (Figura 41). A bacia é interceptada pelas rodovias estaduais TO-050, TO-020 e TO-030 que dão acesso às regiões norte, sul e leste do Estado.

No território da bacia hidrográfica há três unidades de conservação: a Reserva Particular do Patrimônio Natural - RPPN Bela Vista que possui 58,11 ha; o Parque Estadual do Lajeado com 89,68 ha e; a APA Serra do Lajeado com 32.817,68 ha. Essa APA tem como objetivo 
principal proteger os mananciais que abastecem a cidade de Palmas, bem como ordenar a expansão urbana, próxima à encosta da serra. Aproximadamente 5.185,85 ha do território da bacia consistem em áreas urbanas do município de Palmas e do Distrito de Taquaruçu.

A escolha da bacia do Ribeirão Taquaruçu como unidade de estudo se justifica pela sua grande importância para o abastecimento público da cidade. Segundo Silva Neto (2011) a bacia é a principal fonte de captação de água para consumo humano do município, sendo responsável por $70 \%$ do abastecimento público da cidade, abrangendo os bairros Taquaralto, Jardins Aureny I, II, III e IV e, parte da região central de Palmas. Nessa bacia se localiza a principal estação de tratamento de água da capital (ETA-06), operada pela Companhia de Saneamento do Tocantins SANEATINS/BRK Ambiental, atendendo aproximadamente 50 mil aglomerados familiares.

\section{Materiais e Métodos}

\subsection{Modelação Matemática e Hidrológica}

A aplicação do SAD-IPH envolve as seguintes etapas: Pré-processamento ou discretização da bacia; Definição dos atributos de disponibilidade de água para cada trecho de rio; Definição de parâmetros gerais de simulação; Introdução de procuras por consumo e lançamentos de efluentes; Cálculo das condições de quantidade e qualidade em cada trecho de rio e; Análise e visualização dos resultados (KAYSER, 2011).

Na etapa de pré-processamento ou discretização da bacia, tem-se como produto final um arquivo vetorial denominado rede de drenagem, que representa a drenagem de uma bacia graficamente segmentada em vários trechos individuais conectados em confluências. Cada trecho de drenagem possui um conjunto de atributos, que são as variáveis que caracterizam o trecho, quais sejam: direções de escoamento; área de drenagem; rede de drenagem; definição de trechos de rios; comprimento de cada trecho de rio; comprimento e largura do rio principal; declividade e definição das sub-bacias (PEREIRÁ PESSOA, 2010; SILVA, 2014).

Os dados de vazão são obtidos a partir de simulações no modelo hidrológico MGBIPH por se tratar de uma alternativa mais robusta em relação ao emprego das equações de regionalização, onde são estabelecidas curvas de regressão ou curvas de probabilidade que 
sejam função da área contribuinte de cada trecho. Como dado de saída, o modelo gera uma série de vazões para cada segmento da bacia, correspondente ao período dos dados hidrológicos e meteorológicos utilizados. Esses dados são tratados estatisticamente para o estabelecimento de curvas de permanência, e definindo-se uma permanência específica, gera-se então um único valor de vazão para cada trecho da bacia. Esses valores são atributos da rede de drenagem (KAYSER, 2011). A vazão associada a cada trecho pode ser a vazão Q90, a Q7,10, ou outra vazão de referência. O programa também permite a definição de uma vazão de referência diferente para cada mês do ano (RIO GRANDE DO SUL, 2011).

A introdução das demandas consuntivas e de lançamento de efluentes é feita a partir de dois módulos distintos do SAD-IPH. Esses dados são adicionados ao sistema conectando usuários de água aos trechos de rio. Esse processo é realizado por meio da criação de um arquivo vetorial de pontos sobre a rede de drenagem representando estes usuários, e posterior inserção destes pontos na rede, onde será lido o código do trecho mais próximo onde foi lançado cada ponto. Após o preenchimento dos atributos dessas demandas e lançamentos (vazão retirada, vazão efluente, concentrações), os dados são unidos com a tabela de atributos, de acordo com o código no qual o ponto foi inserido (RIO GRANDE DO SUL, 2011; SILVA, 2014).

No módulo quantitativo, após a inserção na tabela de atributos da vazão total demandada por todos os usuários ligados a cada trecho de rio e a todos os trechos situados à montante, podem ser executadas equações de balanço para verificação da disponibilidade hídrica no local e do efeito da inclusão de um novo usuário nos trechos a jusante do mesmo (PEREIRÁ PESSOA, 2010). Para tanto, após a inserção de um novo usuário o sistema executa um algoritmo que calcula o fator de comprometimento, para todos os trechos da rede de drenagem. Após o referido cálculo, o SAD classifica os valores obtidos em cinco faixas de comprometimento e para cada faixa o programa atribui uma cor.

Para a modelagem da qualidade da água da bacia, utiliza-se o módulo SAD-QUAL, que opera em regime permanente de vazões e desconsidera os efeitos de dispersão e advecção, focando nas transformações cinéticas que ocorrem em cada parâmetro. A operacionalização do modelo se dá fundamentalmente pela interação entre o banco de dados geoespacial da bacia hidrográfica e o banco de dados dos usuários de lançamento de efluentes. Para cada trecho de rio são realizados cálculos de mistura de vazões provenientes de montante e 
aportadas ao trecho, mistura com os lançamentos realizados no trecho e cálculo de decaimento de poluentes. Após a mistura dos efluentes, e considerando que esses estejam localizados no ponto mais a montante do segmento, o modelo analisa o efeito das transformações que ocorrem em cada parâmetro simulado ao longo do trecho (SILVA, 2014).

A interpretação dos dados é facilitada por meio da análise visual de gráficos. O SAD apresenta dois tipos de gráficos: os de análise temporal e os de análise espacial. A análise temporal considera todas as informações contidas em um único trecho e demonstram os cenários mensais em forma de gráfico. Já a análise espacial avalia os dados contidos dentro do intervalo de trechos, sendo que para isso é preciso estabelecer o trecho inicial e o final para a geração dos gráficos. O SAD ainda permite a visualização dos resultados de uma forma simples e prática que consiste na elaboração de mapas da rede de drenagem, em que as cores de rios estão associadas ao grau de comprometimento da disponibilidade hídrica e do Índice de Qualidade da Água - IQA da bacia hidrográfica (PEREIRÁ PESSOA, 2010).

Anteriormente à simulação no modelo SAD-IPH, foi realizada a discretização da bacia hidrográfica para a obtenção de arquivos vetoriais. O Modelo Digital de Elevação - MDE utilizado no processo de discretização se refere a uma imagem do sensor ASTER (Advanced Spaceborne Thermal Emission and Reflection Radiometer) com resolução espacial de 30×30m, com acurácia vertical de 16m e, a base cartográfica utilizada possui escala 1:25.000 do Projeto de Atualização Cartográfica e Mapeamento do Uso do Solo do Município de Palmas - TO.

Os arquivos gerados nessa etapa de pré-processamento, bem como dados climáticos provenientes de 02 estações meteorológicas operadas pelo INMET, dados pluviométricos de 04 estações pluviométricas e dados fluviométricos de 06 estações monitoradas pela Companhia de Saneamento do Tocantins foram usados na aplicação do Modelo Hidrológico de Grandes Bacias - MGB-IPH, no qual foi obtida a disponibilidade hídrica da bacia do ribeirão Taquaruçu Grande. Finalizadas essas etapas, iniciou-se a aplicação do modelo SAD$\mathrm{IPH}$.

Para a simulação do módulo quantitativo do SAD-IPH foram incluídas as informações dos usuários da água da bacia, incluindo a identificação do usuário, as coordenadas geográficas 
do ponto de captação, o uso a que se destina a água captada e a vazão demandada. Esses dados são resultantes do levantamento de campo efetuado em 404 propriedades no período compreendido de 09/05/2014 a 07/08/2015. Além disso, foram inseridas as regras de outorga definidas pelo órgão estadual de meio ambiente que efetua a gestão dos recursos hídricos - NATURATINS, onde a vazão de referência é a $Q_{90}$, essa é a vazão em que, estatisticamente, em $90 \%$ do tempo é igual ou maior do que esse valor, esse tipo de vazão é muito usado na gestão de recursos hídricos para que se garanta disponibilidade hídrica aos usuários na maior parte do tempo sem maiores conflitos pelo uso da água. O limite de vazão outorgável corresponde a $75 \%$ da Q90 e a vazão máxima requerida por usuário não pode ultrapassar 25\% da Q9o. Essas regras e critérios foram considerados por meio da interface mencionada que indicou esses limites como coeficientes nos cálculos efetuados.

\subsection{Construção dos cenários}

A Foram estabelecidos três diferentes cenários para a bacia do ribeirão Taquaruçu, onde foram modificados apenas os dados de demanda da água.

O Cenário Atual 1 representa a situação presente dos recursos hídricos no que tange à quantidade de água demandada na bacia hidrográfica. Assim, o objetivo dessa simulação foi avaliar as condições atuais dos recursos hídricos da bacia e dos elementos e fatores a eles vinculados, bem como analisar o seu histórico e as causas da atual situação.

O Cenário Futuro 2 analisa a evolução da situação dos recursos hídricos da bacia e de seus aspectos condicionantes, detectados e avaliados na condição atual em um horizonte temporal de 10 anos (2015-2025). Incorpora as tendências e projeções passíveis de medição, como o aumento da demanda da água da bacia em função do aumento populacional, considerando os critérios de outorga da bacia. Cabe destacar que este cenário incorpora apenas projeções de crescimento de demanda dos usos abastecimento urbano, abastecimento rural e dessedentação animal, visto que esses são os usos mais expressivos existentes na bacia.

O Cenário Alternativo 3 levou em consideração a análise da situação atual (cenário 1) e seus fatores intervenientes (captações irregulares, implantação de barragens no leito dos rios, 
microparcelamento do solo rural, etc.), bem como a projeção de sua evolução (cenário 2), para um horizonte temporal de 20 anos (2015 - 2035).

Assim, os cenários 2 e 3 permitem avaliar a capacidade do sistema hídrico de suportar a procura estimada na bacia para diferentes horizontes temporais, considerando a disponibilidade de água definida por critérios de outorga.

Para tanto, foram utilizados os dados de projeção populacional do município para um horizonte de 20 anos (2015-2035), contemplados no Plano Municipal de Saneamento (PALMAS, 2014). Essa projeção levou em consideração as taxas geométricas de crescimento anual (TGCA) decrescentes com base nas informações de projeção populacional mais recente realizada pelo IBGE. Para a estimativa do consumo de água da população urbana atendida pelas duas ETAs instaladas na bacia, considerou-se um consumo per capita de 250 L/hab.dia, valor adotado pela Companhia de Saneamento do Tocantins - SANEATINS/BRK Ambiental para moradores da área urbana. Assim, utilizou-se a Equação a seguir para estimar a vazão média diária para o período avaliado:

$$
Q_{m}=\frac{P * q}{86400^{1}}
$$

Onde:

$Q_{m}=$ vazão média em L/s;

$P=$ população urbana (hab.);

$q=$ consumo per capita em L/hab.dia;

Como a projeção deve considerar apenas a população servida pela água proveniente da bacia do ribeirão Taquaruçu, foram feitas as seguintes ponderações: a ETA 006, situada na bacia, atende $70 \%$ da população urbana de Palmas e a ETA $007,100 \%$ da população urbana residente no distrito de Taquaruçu.

\footnotetext{
${ }^{1} \mathrm{O}$ valor 86400 é para a conversão do consumo em dia para a vazão em segundos, um dia tem 86400 segundos
} 
Para a projeção da demanda hídrica para o abastecimento da população rural, adotou-se o consumo per capita de 150 L/hab.dia (VON SPERLING, 1995). Em seguida, foram determinadas as demandas para a população rural, a partir do produto do consumo per capita pela respectiva população rural projetada para a bacia, adotando-se taxas de crescimento, que segundo o IBGE equivalem a 1.0\% a.a.

A projeção da demanda hídrica para a dessedentação animal levou em consideração os dados obtidos no levantamento de campo, além de uma taxa geométrica de crescimento de 1\% a.a, adotado pela Secretaria Municipal da Agricultura e Desenvolvimento Rural (2010).

\section{Resultados e discussões}

A seguir são apresentados os resultados e discussões deste trabalho. Vale ressaltar que a Q9o é sempre calculada em função de um determinado período para uma série histórica, o que pode apresentar resultados bem diferentes, e com isso dar uma falsa sensação de segurança hídrica.

Normalmente é calculada uma vazão $Q_{90}$ anual, que considera uma vazão média do ano ao longo de uma série histórica de dados, porém há regiões como a de estudo deste artigo, em que as vazões disponíveis mudam muito do período chuvoso, em que há mais água, para períodos secos em que há maior escassez hídrica. Para verificar melhor essa discrepância, os resultados são apresentados para uma $Q_{90}$ anual, e para $Q_{90}$ de período seco, representada pelo mês de outubro e outra Q9o para o período chuvoso, representada pelo mês de março.

Esse tipo de análise ajuda a montar uma estrutura de gestão de recursos hídricos com regras mais restritivas no período seco e menos restritivas no período chuvoso, com isso se garante uma maior segurança hídrica aos usuários outorgados e uma maior disponibilidade de água no período chuvoso.

Como descrito na metodologia, os resultados e discussão são apresentados para os três cenários descritos anteriormente e com esses três tipos de $Q_{90}$, para além de discutir sobre os riscos temporais e espaciais da disponibilidade hídrica na bacia, são também feitos à luz dessas três possibilidades de vazões de referência $\left(Q_{90}\right)$. 


\subsection{Cenário 1 - Disponibilidade Hídrica x Demanda Atual}

A demanda atual de água da bacia foi aferida por meio do levantamento de campo efetuado em 404 propriedades, entretanto, desse total, apenas os dados de 295 propriedades foram validados para constituir o arquivo de usuários do SAD. O resultado deste levantamento pode ser verificado na Tabela 1.

Tabela 1. Demanda atual de água na bacia do ribeirão Taquaruçu Grande

\begin{tabular}{|l|c|}
\hline \multicolumn{1}{|c|}{ USO } & DEMANDA $\mathbf{~ ( ~}^{\mathbf{3}} \mathbf{/ s} \mathbf{~}$ \\
\hline Abastecimento urbano & 0,714000 \\
\hline Abastecimento rural & 0,005727 \\
\hline Consumo animal & 0,001676 \\
\hline Piscicultura & 0,000001 \\
\hline Irrigação & 0,000016 \\
\hline Serviços & 0,000669 \\
\hline Recreação & 0,000000 \\
\hline Industrial & 0,004278 \\
\hline TOTAL & $\mathbf{0 , 7 2 6 3 6 7}$ \\
\hline
\end{tabular}

Esse Como visto, o abastecimento urbano é o uso que mais demanda água na bacia, consumindo $98,29 \%$ da demanda hídrica total. Na sequência aponta-se o abastecimento rural, o industrial e o consumo animal. Os demais usos mostraram-se pouco expressivos em termos de consumação de água.

Assim, para avaliar a interferência do consumo de água pelos usuários na disponibilidade hídrica da bacia e verificar se os limites para captação estabelecidos pela legislação estadual estão sendo respeitados, foram simuladas diferentes situações. Em todas as simulações utilizou-se a vazão Q9o como referência e, a demanda hídrica foi considerada estável ao longo do ano.

Na primeira simulação observa-se a interferência do consumo atual na disponibilidade hídrica - $Q_{90}$ anual (Figura 2). Analisando esta situação, pode-se verificar que a maioria dos corpos hídricos da bacia está em condição favorável, onde o valor máximo da vazão captada em cada trecho representa apenas $1 \%$ da $Q_{90}$. Alguns afluentes dos ribeirões Taquaruçu Grande e Taquaruçu Pequeno, além de um trecho expressivo do ribeirão Taquaruçu Pequeno encontram-se com o limite de 1 a $25 \%$ da Q9o comprometidos. 


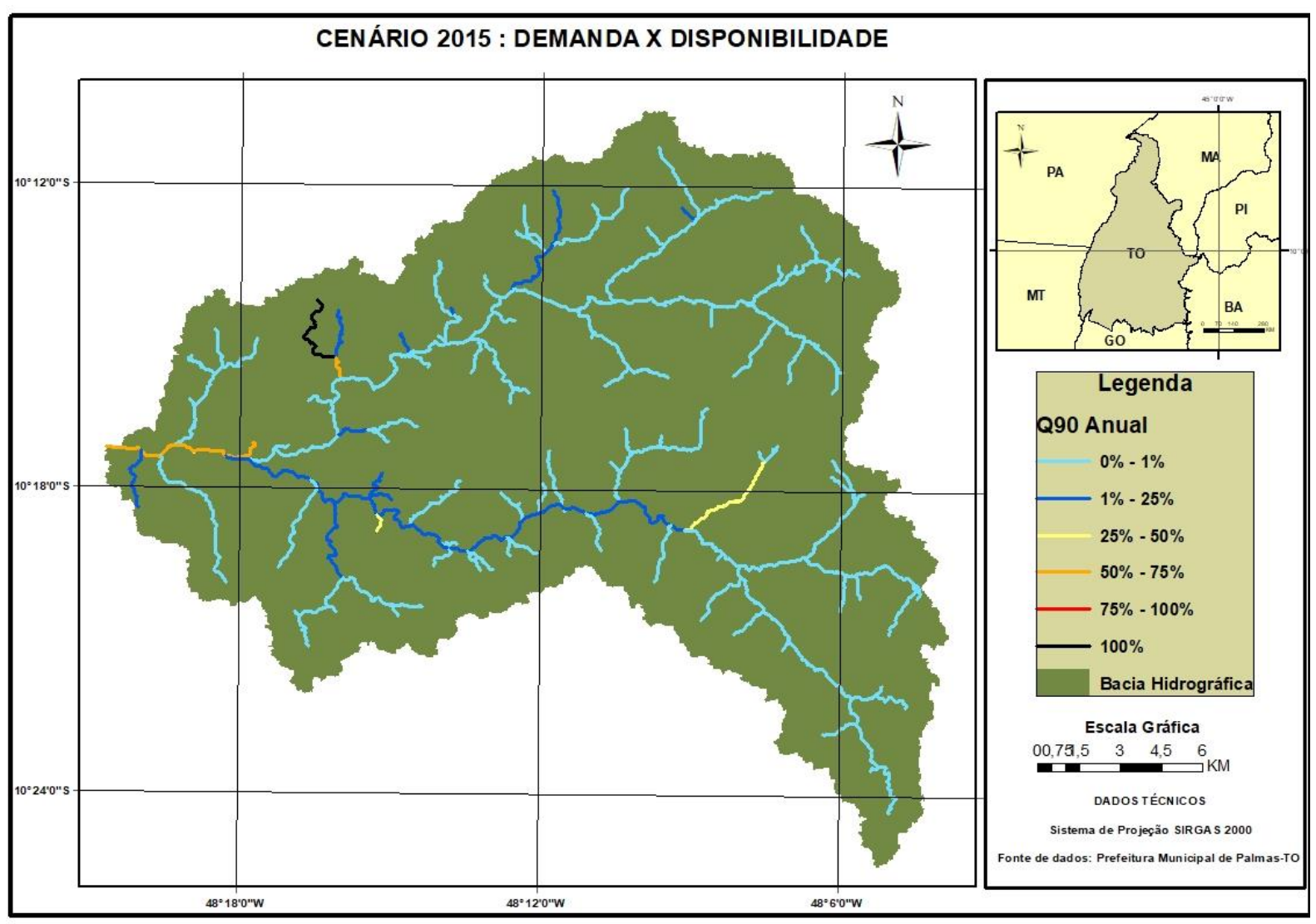

Figura 2. Mapa da Vazão $Q_{90}$ anual x demanda atual.

Entretanto, o córrego Roncador, tributário do Taquaruçu Pequeno, onde é realizada a captação da Companhia de Saneamento do Tocantins - SANEATINS/BRK Ambiental para o abastecimento público do Distrito de Taquaruçu, já possui cerca de 25 a $50 \%$ de sua vazão de referência utilizada. Considerando que nesse trecho há apenas dois usuários cadastrados e, que a Companhia de Saneamento capta o volume mais significativo de água $-0,014 \mathrm{~m}^{3} / \mathrm{s}$ ou $14 \mathrm{~L} / \mathrm{s}$, pode-se afirmar que provavelmente essa captação, outorgada pelo órgão gestor estadual, está fora dos limites estabelecidos pela legislação estadual, onde um único usuário não pode captar volume maior que $25 \%$ da vazão de referência do curso hídrico.

Ainda há dois trechos em que a $Q_{90}$ encontra-se comprometida entre 50 e $75 \%$. O primeiro se refere a um pequeno trecho de um tributário do ribeirão Taquaruçu Grande, onde donos de chácaras captam água para abastecimento humano e dessedentação animal e, o outro, maior, está situado após a confluência dos ribeirões Taquaruçu Grande e Taquaruçu Pequeno, no qual a Companhia de Saneamento realiza a captação de $0,7 \mathrm{~m}^{3} / \mathrm{s}$ ou $700 \mathrm{~L} / \mathrm{s}$ para o abastecimento da região sul de Palmas. Ressalta-se que a vazão ecológica, 
correspondente a $25 \%$ da $Q_{90}$, ainda está sendo mantida nos dois trechos, todavia, nenhuma outra captação pode ser autorizada pelo órgão gestor, visto que o limite de $75 \%$ da $Q_{90}$ fora atingido. Destaca-se que a captação efetuada pela Companhia de Saneamento ocorre em uma barragem de acumulação, situação em que se pode captar até $90 \%$ da $Q_{90}$ e, um único usuário pode captar até $25 \%$ desse percentual.

Para esse cenário referente à $Q_{90}$ anual, apenas um tributário do ribeirão Taquaruçu Grande apresentou o comprometimento total de sua vazão de referência, não sendo preservado nem o limite da vazão ecológica do corpo hídrico. Ali são realizadas captações irregulares de água por chacareiros, que a utilizam para o desenvolvimento de suas atividades, o que pode levar a conflitos pelo uso da água no futuro, já que a sustentabilidade do recurso hídrico não está sendo mantida.

Na sequência serão apresentados a situação da Q90, para o mês de maior disponibilidade hídrica, março, que representa o período chuvoso e para o mês de maior escassez hídrica, outubro, que representa o período seco, possibilitando assim, propor medidas de gestão que levem à sustentabilidade da bacia.

O balanço hídrico para o mês de março (Figura 3) representa bem o período com maiores vazões no rio, por isso a disponibilidade hídrica da bacia é mais alta. Apenas pequenos trechos do ribeirão Taquaruçu Pequeno têm sua disponibilidade hídrica comprometida entre 1 a $25 \%$ de sua $Q_{90}$ comprometida e grande parte da bacia está na faixa de 0 a $1 \%$, ou seja, a vazão do rio em março é maior, refletindo no aumento da $Q_{90}$ e consequente menor interferência das captações dos usuários.

O balanço hídrico do mês de outubro se mostrou o mais crítico do ano, como pode ser observado na Figura 4. Aqui verifica-se que no córrego Roncador a disponibilidade hídrica diminuiu e a $Q_{90}$ passou a apresentar um grau de comprometimento de 50 a $75 \%$. Isso é preocupante porque é o trecho que abastece o distrito de Taquaruçu, o que indica que em um futuro próximo poderá faltar água para essa comunidade. 


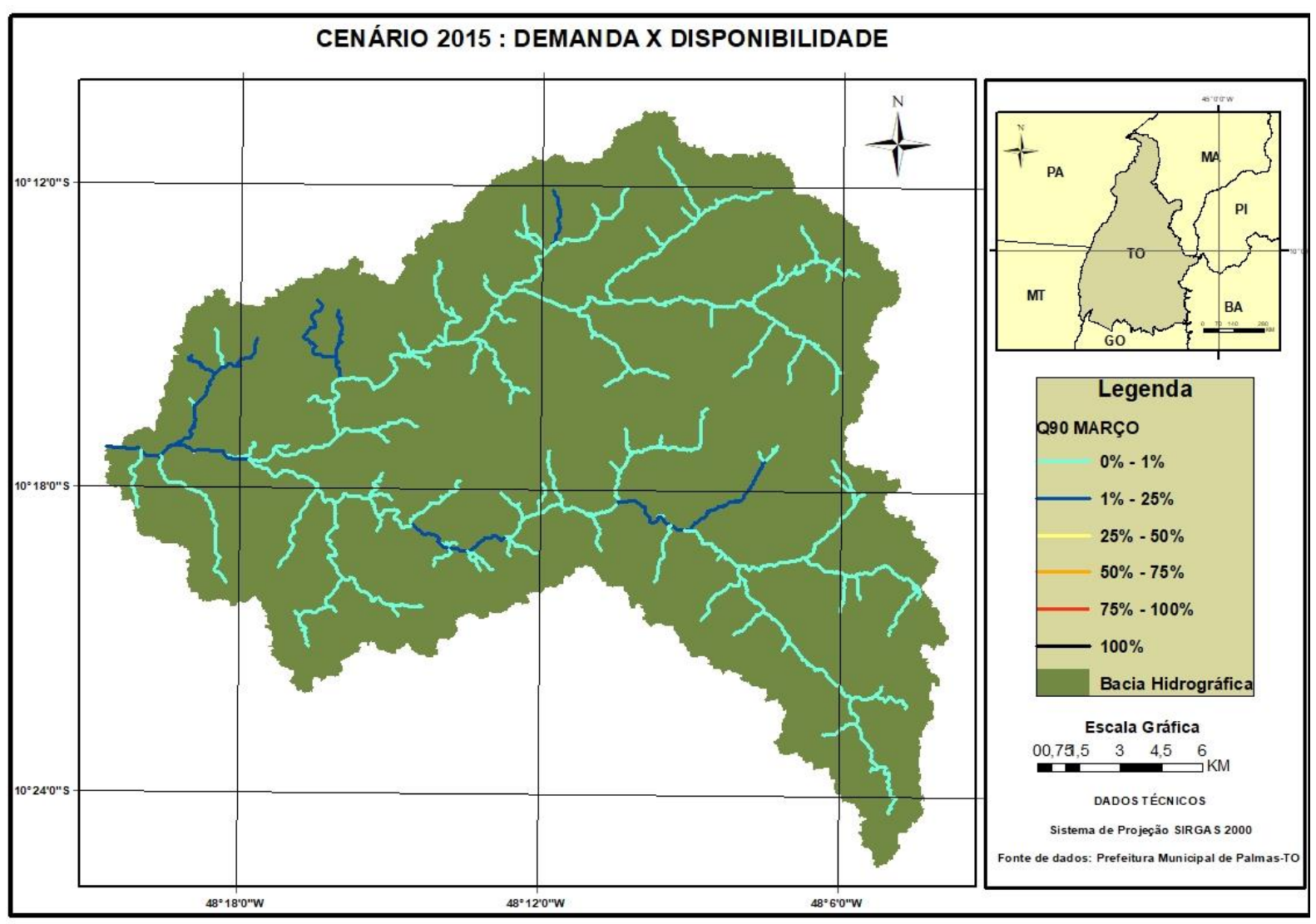

Figura 3. Mapa de comprometimento da vazão $Q_{90}$ março x demanda atual.

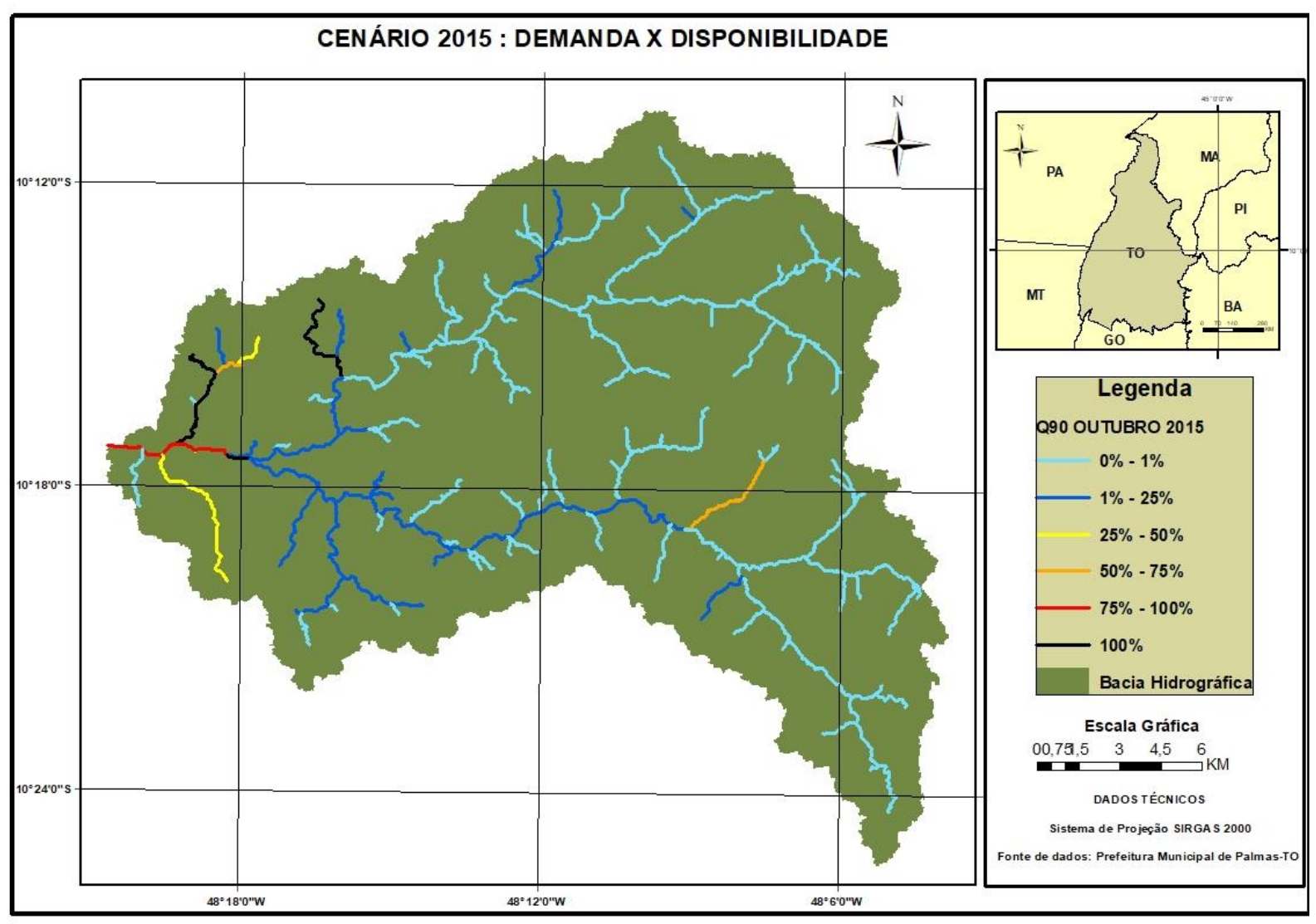

Figura 4. Mapa de comprometimento da vazão $Q_{90}$ outubro x demanda atual 


\subsection{Cenário 02 - Disponibilidade Hídrica x Demanda em 2025}

A estimativa do crescimento da demanda hídrica da população rural e dos animais que habitam a bacia, bem como da população urbana atendida pelas ETA 007 e ETA 006 foi efetuada com base em dados de projeção demográfica oficiais. Ressalta-se que os demais usos existentes na bacia não foram considerados na projeção, em função de serem pouco expressivos. No caso do uso industrial, que é considerado relevante, sua projeção não foi realizada por não existirem dados oficiais que subsidiem a sua estimativa.

O Quadro 1 apresenta os dados relativos à estimativa da evolução da demanda hídrica da bacia em estudo, para o horizonte temporal de dez anos (2015-2025), considerando os três usos mais significativos, existentes na bacia. Ressalta-se que a demanda dos demais usos, considerados pouco expressivos, foi mantida constante em todo o período avaliado.

Quadro 1. Projeção de demanda hídrica da bacia para o período de 2015 a 2025.

\begin{tabular}{|c|c|c|c|c|c|}
\hline \multirow{2}{*}{ Ano } & \multicolumn{3}{|c|}{ Usos } & $\begin{array}{c}\text { Total } \\
\left(\mathbf{m}^{3} / \mathbf{s}\right)\end{array}$ \\
\cline { 2 - 6 } & $\begin{array}{c}\text { Dessed. animal } \\
\left(\mathbf{m}^{3} / \mathbf{s}\right)\end{array}$ & $\begin{array}{c}\text { Abast. } \\
\text { rural } \\
\left(\mathbf{m}^{3} / \mathbf{s}\right)\end{array}$ & \multicolumn{2}{|c|}{$\begin{array}{c}\text { Abast. urbano } \\
\left(\mathbf{m}^{3} / \mathbf{s}\right)\end{array}$} & $\begin{array}{c}\text { Demais } \\
\text { usos } \\
\left(\mathbf{m}^{3} / \mathbf{s}\right)\end{array}$ \\
\hline 2015 & 0,00167 & 0,00573 & 0,714 & 0,00536 & 0,72637 \\
\hline 2016 & 0,00169 & 0,00578 & 0,734 & 0,00536 & 0,74697 \\
\hline 2017 & 0,00171 & 0,00584 & 0,755 & 0,00536 & 0,76818 \\
\hline 2018 & 0,00173 & 0,00590 & 0,777 & 0,00536 & 0,78999 \\
\hline 2019 & 0,00174 & 0,00596 & 0,799 & 0,00536 & 0,81243 \\
\hline 2020 & 0,00176 & 0,00602 & 0,822 & 0,00536 & 0,83552 \\
\hline 2021 & 0,00178 & 0,00608 & 0,845 & 0,00536 & 0,85808 \\
\hline 2022 & 0,00179 & 0,00614 & 0,867 & 0,00536 & 0,88011 \\
\hline 2023 & 0,00181 & 0,00620 & 0,888 & 0,00536 & 0,90159 \\
\hline 2024 & 0,00183 & 0,00626 & 0,909 & 0,00536 & 0,92250 \\
\hline 2025 & 0,00185 & 0,00633 & 0,929 & 0,00536 & 0,94284 \\
\hline
\end{tabular}

Avaliando os dados do quadro 1, pode-se aferir que no decorrer dos próximos dez anos a demanda hídrica da bacia aumentará aproximadamente $29,8 \%$.

Ao avaliar a Figura 5, verifica-se que se não forem adotadas medidas de gestão dos recursos hídricos da bacia em estudo, o balanço hídrico irá se agravar em 2025, como já era esperado. Essa constatação se refletiu na simulação com a Q Q anual - Figura 5. 


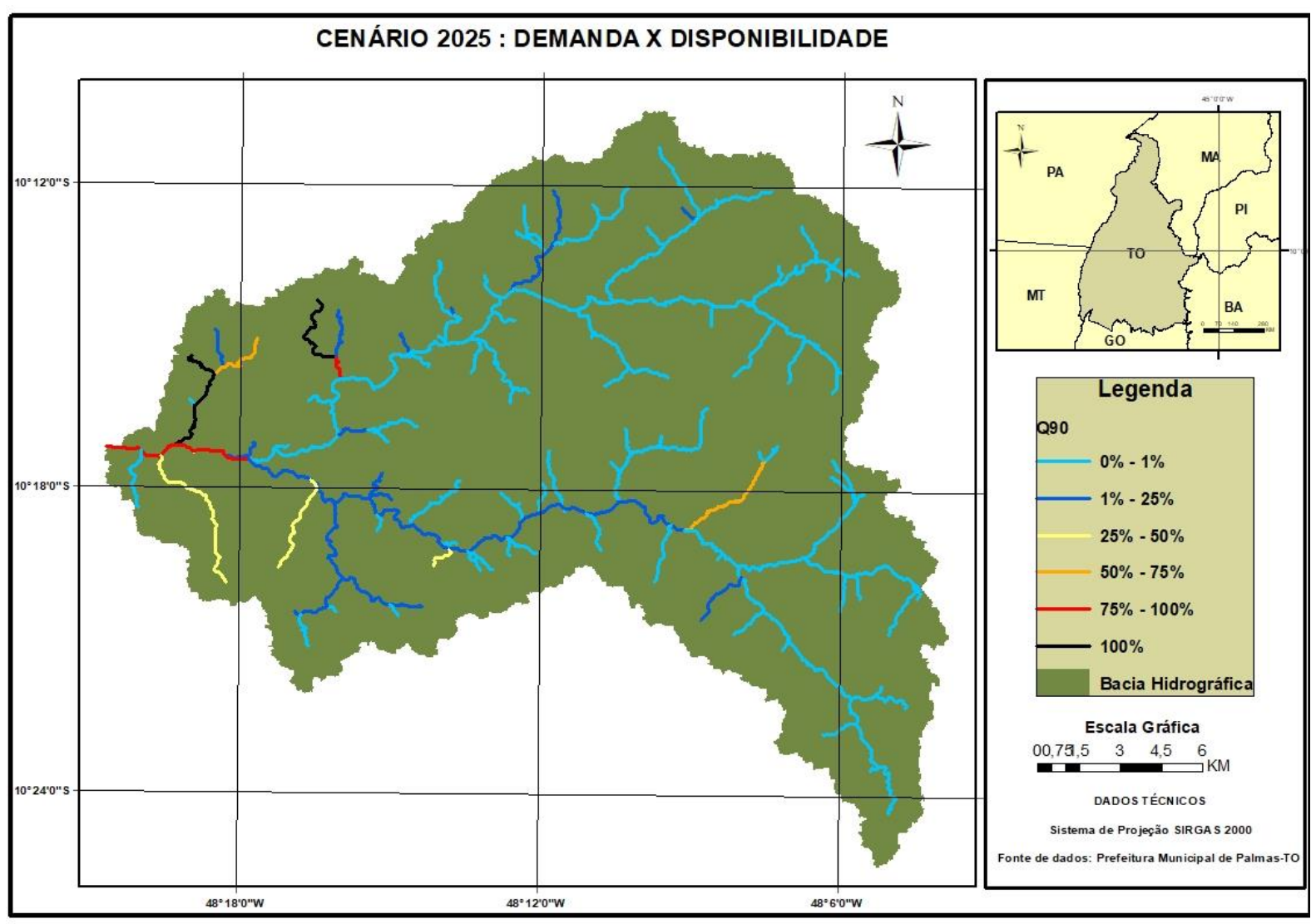

Figura 7. Mapa de comprometimento da vazão Q90 anual x demanda em 2025.

Comparando o balanço hídrico referente ao cenário de 2025 (Figura 5) com o cenário 1 atual (Figura 2) percebe-se que houve aumento da criticidade de 17 trechos, sendo destacadas as principais.

Córrego Roncador, utilizado pela Companhia de Saneamento para o abastecimento público do Distrito de Taquaruçu, que teve o limite de uso da Q9o aumentado de 25 a 50\% para 50 a 75\%. O cenário de abastecimento público nesse distrito tende a ficar preocupante, caso não sejam tomadas medidas de gestão dos recursos hídricos.

Trecho do ribeirão Taquaruçu, situado a jusante da ETA 006, houve aumento do grau de comprometimento de sua vazão de referência de 50 a $75 \%$ para 75 a 100\%. Na mesma situação se encontra um pequeno trecho de um afluente do ribeirão Taquaruçu Grande, fortemente impactado pelas captações efetuadas por chacareiros.

Trecho do córrego Tiúba apresentou aumento do grau de comprometimento da vazão de referência de 75 a $100 \%$ para $100 \%$ ou mais. Esse e outro trecho de um tributário do ribeirão Taquaruçu Grande, que já apresentou esta configuração no cenário atual, são os 
trechos mais críticos da bacia. Aqui há um total comprometimento da disponibilidade hídrica em que conflitos pelo uso da água são bem caracterizados, há uma necessidade urgente do poder público atuar no sentido de disciplinar os usuários de forma a minimizar os conflitos.

A seguir são apresentados os cenários para os meses de março (figura 6) e outubro (figura 7), para confrontar situações extremas de conforto no comprometimento da disponibilidade hídrica e escassez hídrica.

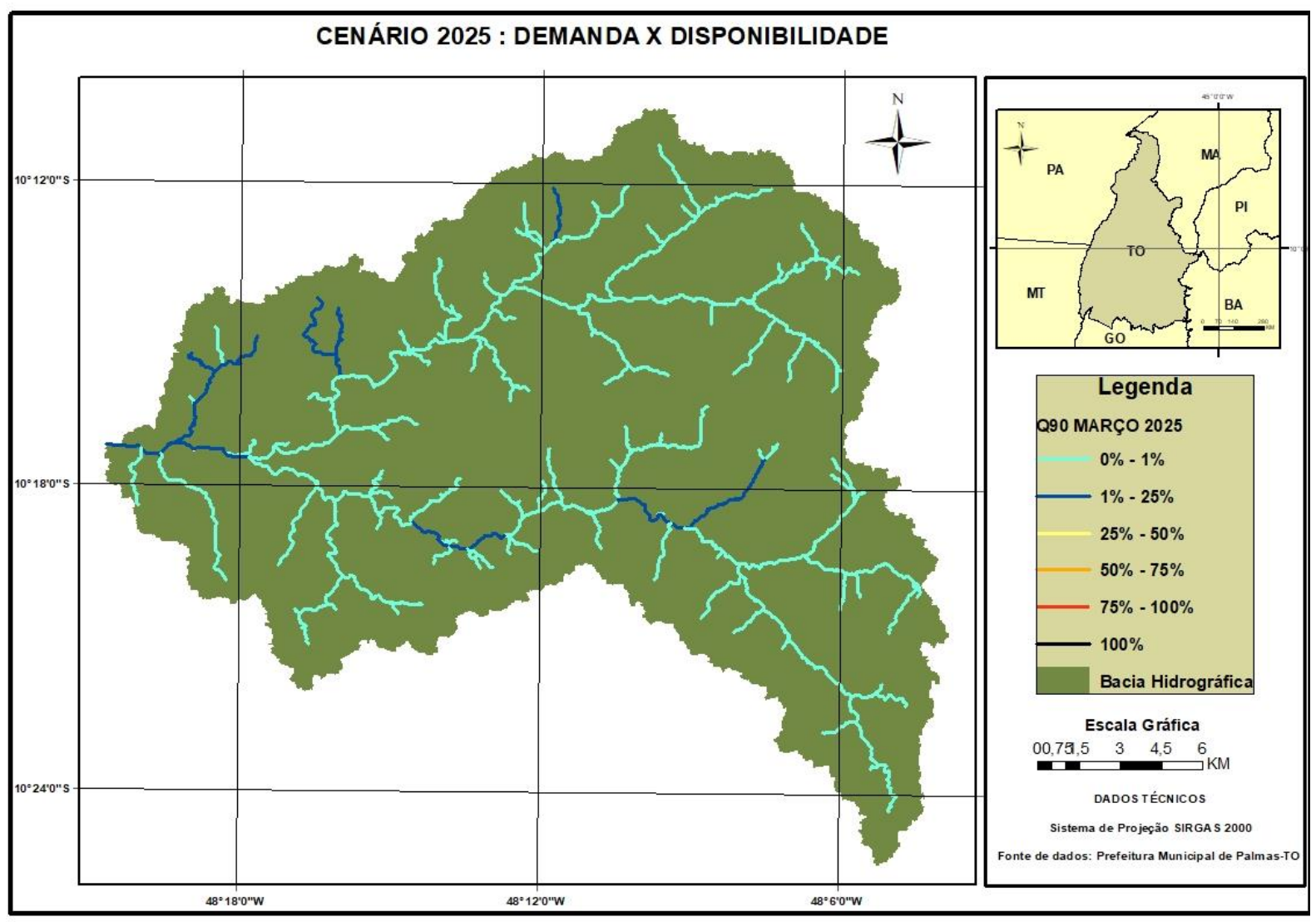

Figura 6. Mapa de comprometimento da vazão $Q_{90}$ março x demanda em 2025.

A disponibilidade hídrica no mês de março é relativamente alta em relação à demanda, sendo assim como pode ser visto no mapa da figura 6 , não há praticamente nenhuma alteração no comprometimento da disponibilidade hídrica em um cenário para 2025 em relação ao cenário de 2015 . Isso se deve ao fato de estar representada uma situação em que as vazões dos rios ainda estão sob efeito do período chuvoso, fazendo assim com que o cenário ainda seja confortável. 
O mapa da figura 7 mostra a situação oposta, em que se reflete o período de estiagem com redução significativa das vazões do rio, fazendo com que a disponibilidade hídrica seja menor, aliado a uma projeção de aumento da demanda, os níveis de comprometimento da Q90 passam a ser mais preocupantes e em mais trechos. Aqui verifica-se um cenário bem mais comprometido da disponibilidade hídrica em relação ao de 2015.

Vale ressaltar que o trecho do córrego Roncador que abastece o distrito de Taquaruçu, no período de estiagem fica em uma situação mais crítica, e seu comprometimento da disponibilidade hídrica passa para a classe de $75 \%$ a $100 \%$. Nesse tipo de situação o risco de racionamento ou interrupção no abastecimento da população é significativo.

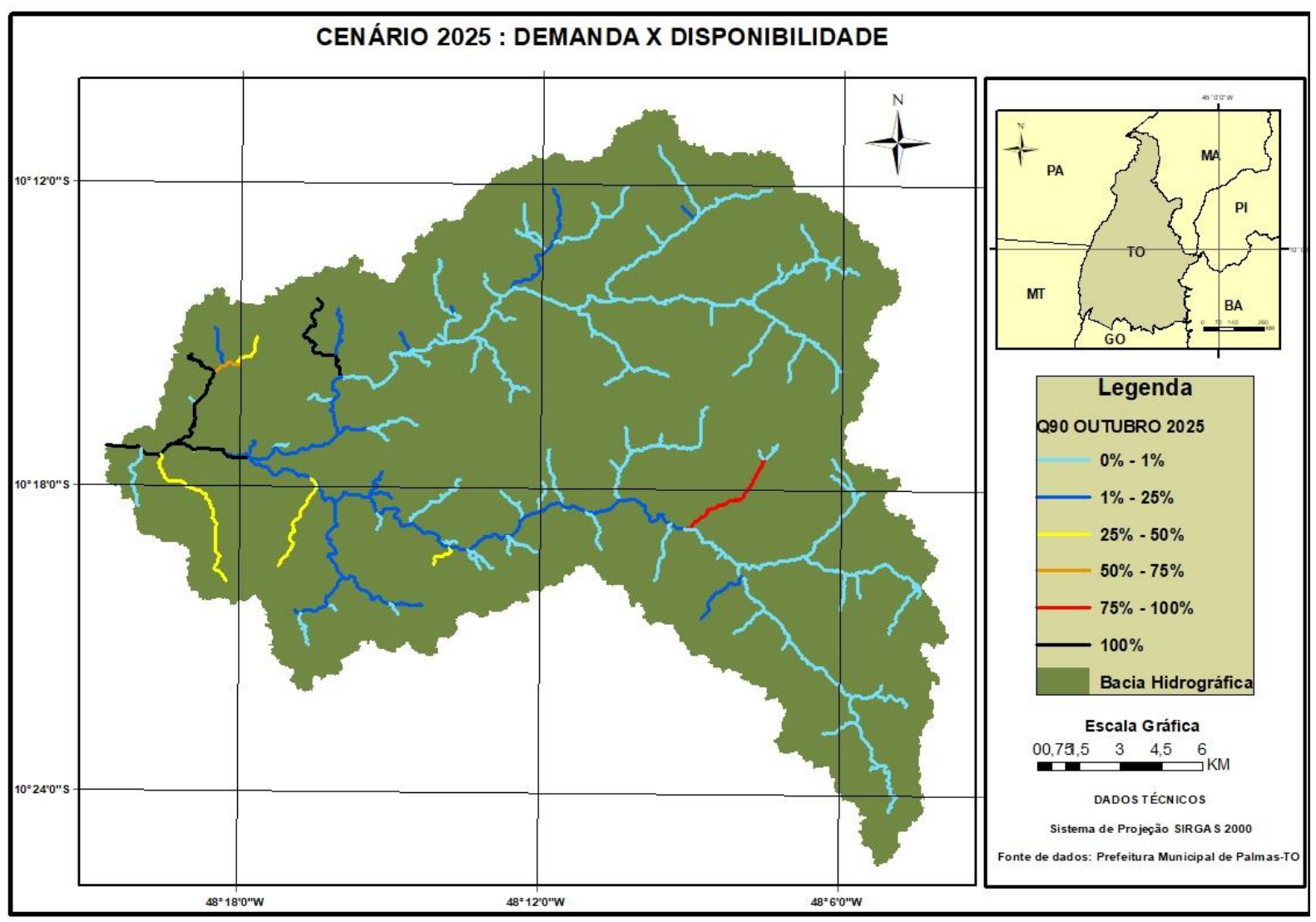

Figura 7. Mapa de comprometimento da vazão Q9o outubro x demanda em 2025.

O comprometimento de mais de $100 \%$ no mês de outubro na região da foz da bacia, onde é feita a captação para a cidade de Palmas é muito preocupante também, a cidade já teve períodos de racionamento e pelo estudo ao que tudo indica a tendência é piorar, se nada for feito. 
Verifica-se aqui no cenário 2 uma situação bem mais desconfortável em relação à disponibilidade hídrica na bacia, principalmente no período de estiagem e notadamente para o abastecimento público, mas há de lembrar que a maioria dos produtores rurais da bacia abastecem as feiras livres da cidade de Palmas, e que caso haja medidas de restrição do uso da água por parte deles para garantir o abastecimento público, a cidade corre um risco de desabastecimento de hortaliças, ou ter a necessidade de abastecer-se de outras regiões, o que encarece os produtos

\subsection{Cenário 03 - Disponibilidade Hídrica x Demanda em 2035}

O Quadro 2 sintetiza os dados obtidos nas projeções efetuadas para 2035, onde é esperado um aumento de 53,42\% da demanda hídrica da bacia no decorrer de 20 anos.

Quadro 2. Projeção de demanda hídrica da bacia para o período de 2015 a 2035.

\begin{tabular}{|c|c|c|c|c|c|}
\hline \multirow{2}{*}{ Ano } & \multicolumn{4}{|c|}{ USOS } & \multirow{2}{*}{$\begin{array}{c}\text { Total } \\
\left(\mathbf{m}^{\mathbf{3}} / \mathbf{s}\right)\end{array}$} \\
\cline { 2 - 5 } & $\begin{array}{c}\text { Dessed. animal } \\
\left(\mathbf{m}^{\mathbf{3}} / \mathbf{s}\right)\end{array}$ & $\begin{array}{c}\text { Abast. rural } \\
\left(\mathbf{m}^{\mathbf{3}} / \mathbf{s}\right)\end{array}$ & $\begin{array}{c}\text { Abast. } \\
\text { urbano } \\
\left(\mathbf{m}^{\mathbf{3}} / \mathbf{s}\right)\end{array}$ & $\begin{array}{c}\text { Demais } \\
\text { usos } \\
\left(\mathbf{m}^{3} / \mathbf{s}\right)\end{array}$ & \\
\hline 2015 & 0,00167 & 0,00573 & 0,714 & 0,00536 & 0,72637 \\
\hline 2016 & 0,00169 & 0,00578 & 0,734 & 0,00536 & 0,74698 \\
\hline 2017 & 0,00171 & 0,00584 & 0,755 & 0,00536 & 0,76818 \\
\hline 2018 & 0,00173 & 0,00590 & 0,777 & 0,00536 & 0,78999 \\
\hline 2019 & 0,00174 & 0,00596 & 0,799 & 0,00536 & 0,81243 \\
\hline 2020 & 0,00176 & 0,00602 & 0,822 & 0,00536 & 0,83551 \\
\hline 2021 & 0,00178 & 0,00608 & 0,845 & 0,00536 & 0,85808 \\
\hline 2022 & 0,00179 & 0,00614 & 0,867 & 0,00536 & 0,88011 \\
\hline 2023 & 0,00181 & 0,00620 & 0,888 & 0,00536 & 0,90159 \\
\hline 2024 & 0,00183 & 0,00626 & 0,909 & 0,00536 & 0.92250 \\
\hline 2025 & 0,00185 & 0,00633 & 0,929 & 0,00536 & 0.94284 \\
\hline 2026 & 0,00187 & 0,00639 & 0,949 & 0,00536 & 0.96260 \\
\hline 2027 & 0,00188 & 0,00645 & 0,968 & 0,00536 & 0.98178 \\
\hline 2028 & 0,00191 & 0,00652 & 0,987 & 0,00536 & 1.00037 \\
\hline 2029 & 0,00193 & 0,00658 & 1,005 & 0,00536 & 1.01838 \\
\hline 2030 & 0,00194 & 0,00665 & 1,022 & 0,00536 & 1.03581 \\
\hline 2031 & 0,00196 & 0,00671 & 1,039 & 0,00536 & 1.05265 \\
\hline 2032 & 0,00198 & 0,00678 & 1,055 & 0,00536 & 1.06892 \\
\hline 2033 & 0,00200 & 0,00685 & 1,070 & 0,00536 & 1.08463 \\
\hline 2034 & 0,00202 & 0,00692 & 1,085 & 0,00536 & 1.09979 \\
\hline 2035 & 0,00204 & 0,00699 & 1,100 & 0,00536 & 1.11439 \\
\hline & & & & & \\
\hline
\end{tabular}


Comparando-se o resultado obtido para o balanço hídrico anual de 2035 (Figura 8) com o do cenário anterior, de 2025 (Figura 5), observa-se que ocorreu apenas a alteração de um pequeno trecho de um tributário do ribeirão Taquaruçu Grande, que em 2025, apresentava o comprometimento de sua $Q_{90}$ anual de 25 a $50 \%$ e, em 2035, esse percentual aumenta para 50 a 75\%. Portanto, a alteração para o balanço hídrico anual da bacia se mostra pouco significativa, embora haja a previsão de aumento expressivo da demanda pelos usuários.

Aqui fica evidente que, quando a disponibilidade hídrica $\left(Q_{90}\right)$ é calculada considerando as vazões de todos os meses do ano de forma conjunta, a percepção de situações críticas desaparece ou é minimizada, não há como analisar as variações sazonais das vazões devido ao período seco e chuvoso. Os comportamentos mais restritivos apontados apresentados na figura 8, em uma tomada de decisão, seriam para o ano todo, o que pode levar a ações que não sejam suficientes para resolver os conflitos no período seco e ao mesmo tempo, poderiam ser muito restritivas para um período chuvoso.

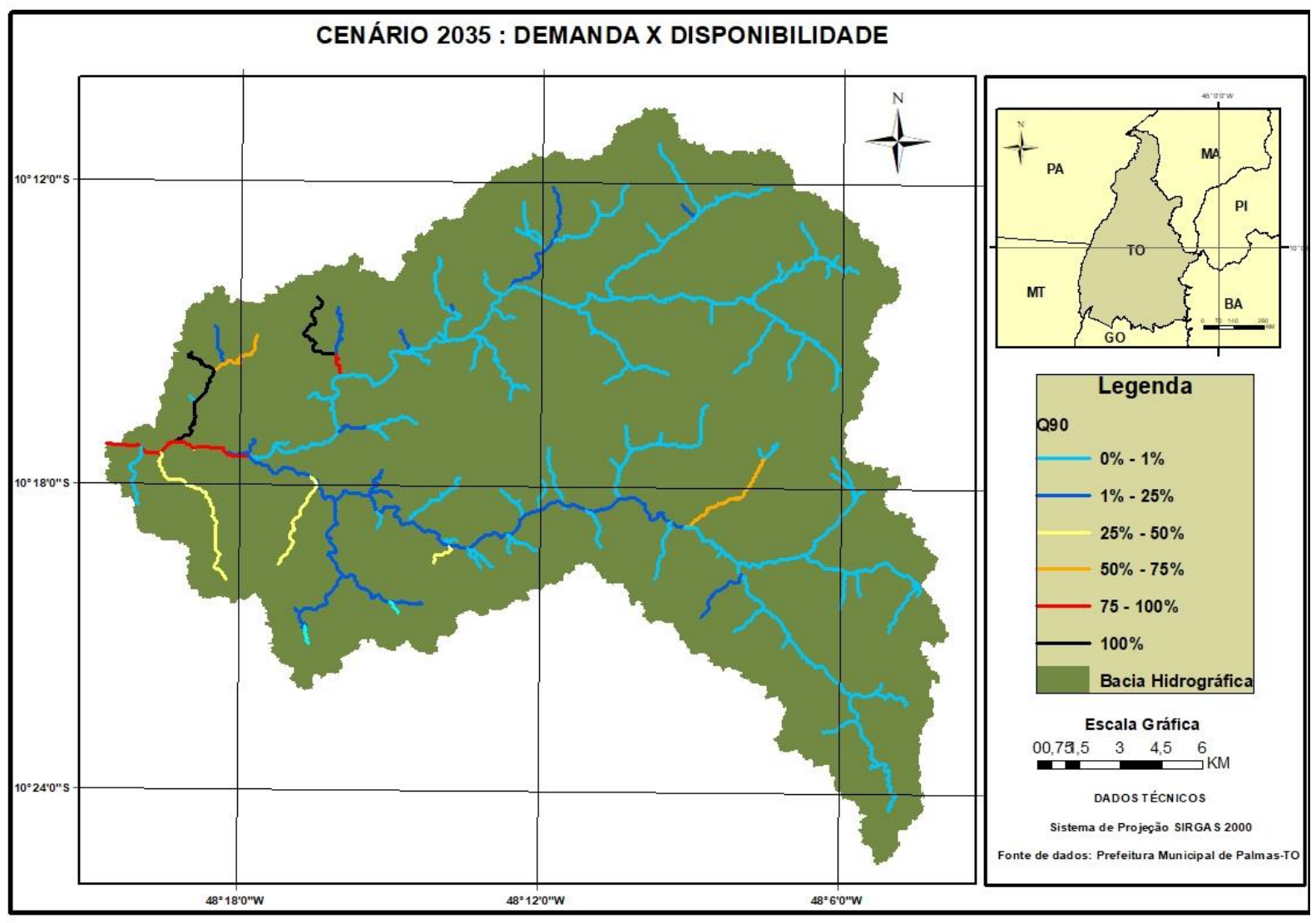

Figura 8. Mapa de comprometimento da vazão $Q_{90}$ anual x demanda em 2035. 
Isso fica bem claro quando analisamos o comprometimento da disponibilidade hídrica para os períodos chuvoso em março (figura 9) e seco em outubro (figura 10).

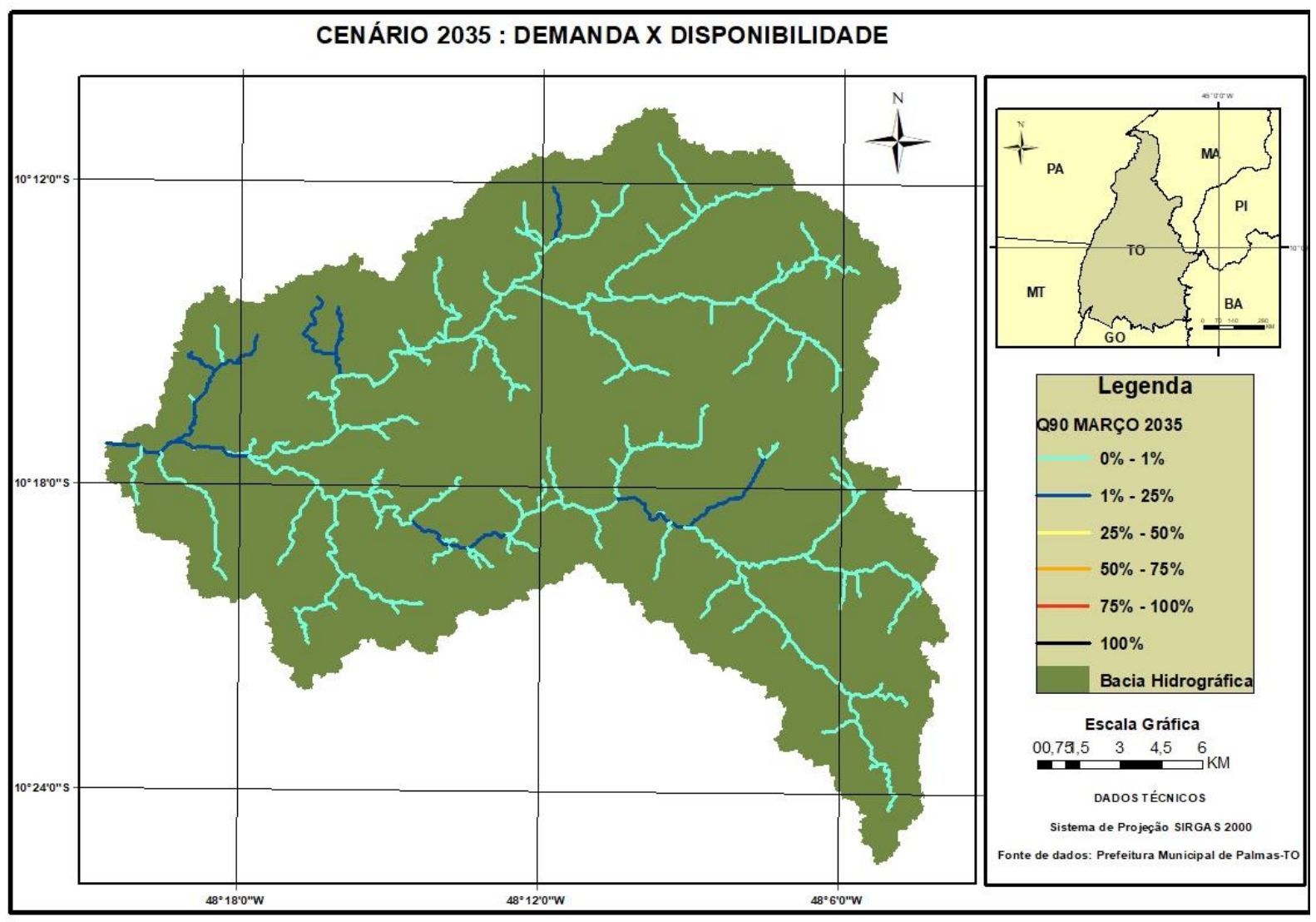

Figura 9. Mapa de comprometimento da vazão Q9o março x demanda em 2035.

As alterações no comprometimento da disponibilidade hídrica para o mês de março com a projeção de demanda de 2035, em quase nada se altera em relação a 2015 e 2025, isso demonstra que no período chuvoso a bacia teria condições de suportar com segurança as projeções das demandas até esse ano. Isso mostra mais uma vez que, quando este mapa é comparado ao da Qgoanual, medidas de gestão dos recursos hídricos com base nos dados anuais tornar-se-iam medidas excessivamente restritivas, uma vez que o mapa da figura 9 aponta para uma situação confortável em relação ao comprometimento da disponibilidade hídrica, o que poderia levar a uma subutilização dos recursos hídricos nesse período.

O cenário apresentado para o mês de outubro de 2035 (figura 10), ao contrário, é muito preocupante, aponta para um colapso no abastecimento público, tanto para o distrito de Taquaruçu como para a cidade de Palmas. Os trechos dos rios em que são feitas essas captações estariam com a disponibilidade hídrica totalmente comprometida, em que não 
haveria nenhuma segurança hídrica para garantir minimamente o abastecimento público da cidade, quanto mais outros tipos de uso.

Para esse cenário, o órgão gestor de recursos hídricos deveria preparar algum tipo de estratégia para se preparar para esse tipo situação, ou não permitir que se chegue a essa situação.

Essa é uma das grandes contribuições da cenarização de possíveis situações de futuro por meio deste tipo de modelagem, a antecipação de situações de futuro não desejadas, as quais podem ser evitadas ou minimizadas com ações planejadas.

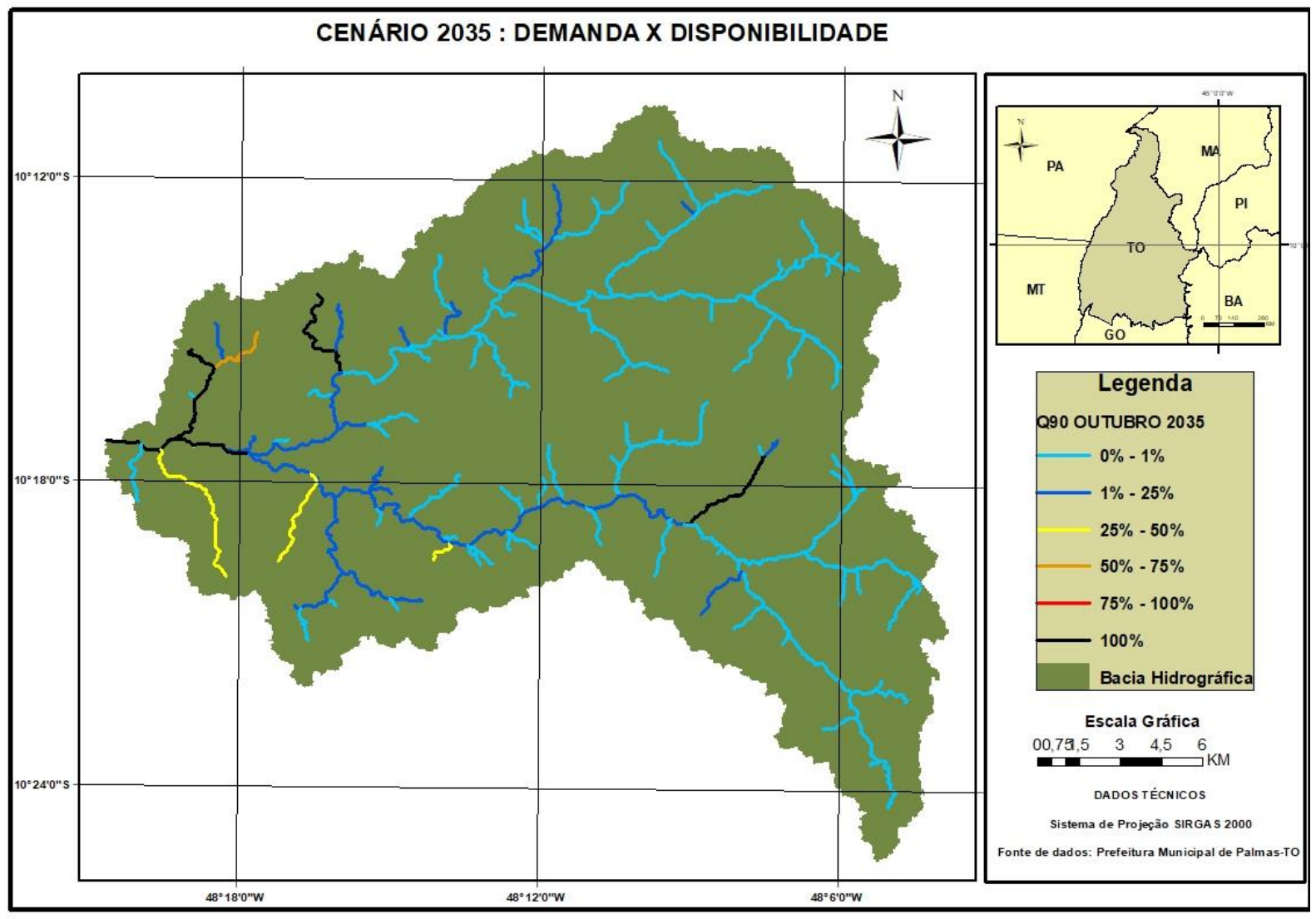

Figura 10. Mapa de comprometimento da vazão Q90 outubro x demanda em 2035.

Os resultados obtidos no desenvolvimento deste estudo permitem concluir que o modelo SAD-IPH se mostrou uma importante ferramenta para tornar as análises dos processos de outorga mais ágeis, eficientes e precisas, visto que a interpretação dos resultados gerados pelo modelo quanto ao impacto das retiradas na disponibilidade hídrica da bacia é de fácil compreensão para os técnicos, pois a visualização dos resultados se dá em mapas da rede 
de drenagem, onde as cores de rios estão associadas ao grau de comprometimento da disponibilidade hídrica.

Além disso, é possível a realização de análises de previsões, por meio da construção de cenários, como a alocação negociada de água na época de estiagem da bacia, permitindo que tanto o órgão gestor quanto o comitê da bacia possam ter acesso a dados antes não disponíveis para a tomada de decisões, incidindo assim, em menos erros nesse procedimento. Em função dessa característica o modelo SAD-IPH tem sido utilizado com sucesso em planos de bacias hidrográficas para embasar as propostas de enquadramento dos recursos hídricos, dentre os estudos realizados, pode-se mencionar: o PBH da bacia do rio Ibicuí, o PBH da bacia do Alto Jacuí, o PBH do rio Santa Maria e o PBH do rio Camaquã, todas situadas no Estado do Rio Grande do Sul, o PBH do rio Tubarão e complexo lagunar no Estado de Santa Catarina e, o PBH da região de Macaé e Rio das Ostras no Estado do Rio de Janeiro.

Como a operacionalização do modelo se dá pela interação entre o banco de dados geoespacial da bacia hidrográfica e o banco de dados dos usuários que realizam captações de água e lançamento de efluentes, o modelo se mostra bastante interativo e dinâmico, visto que novos usuários podem ser cadastrados a qualquer momento, bem como a inserção das regras de outorga de cada Estado, atendendo a demanda dos órgãos gestores.

Pelo fato de se tratar de um programa computacional implantado em uma plataforma SIG gratuita, disponível para download na internet, a sua adesão para o gerenciamento de recursos hídricos pelos órgãos gestores é ainda mais interessante. Essa premissa também foi destacada por Silva et al. (2017), que utilizou o modelo com sucesso na bacia do rio Piracicaba - MG. Todavia, cabe destacar que a utilização do modelo requer que o analista apresente um bom conhecimento técnico em SIG para a correta preparação dos arquivos de entrada.

Entretanto, como o modelo matemático SAD-IPH está em fase de aperfeiçoamento, sugerese que seja viabilizada a interação entre os módulos qualitativo e quantitativo, visto que as captações de água da bacia, efetuadas pelos usuários, diminui a disponibilidade hídrica, afetando a qualidade da água, o que tornará essa simulação mais real. Ainda sugere-se que a entrada dos dados seja mais dinâmica, pois alguns itens do programa ainda não permitem 
a importação de planilhas já preenchidas, o que torna o processo de criação do projeto mais demorado.

\section{Considerações Finais}

O A aplicação do SAD-IPH para a bacia hidrográfica de interesse demonstrou que a utilização da $Q_{90}$ mensal se mostrou mais adequada do que a $Q_{90}$ anual para a gestão dos recursos hídricos, em função das características climáticas do Estado do Tocantins, que possui duas estações bem definidas: seca e chuvosa. Assim, as simulações realizadas com a $Q_{90}$ mensal refletiram melhor a sazonalidade da bacia.

A utilização do SAD-IPH na bacia ainda permitiu verificar que o aumento da demanda hídrica nos próximos 20 anos irá agravar ainda mais o comprometimento da $Q_{90}$ de alguns trechos da rede hidrográfica, principalmente aqueles mais demandados pelos usuários, como o córrego Roncador, onde é realizada a captação para o abastecimento do Distrito de Taquaruçu, o trecho do ribeirão Taquaruçu a jusante da ETA 006, onde a Companhia de Saneamento efetua a captação para o abastecimento de $70 \%$ da população urbana de Palmas, bem como um tributário do ribeirão Taquaruçu Grande, onde vários chacareiros realizam captações. Assim, verifica-se que a Companhia de Saneamento deve buscar de forma emergencial novas alternativas para suprir a demanda de seus usuários, principalmente nos meses de seca da região, onde a disponibilidade hídrica da bacia é baixa. Como medidas para redução do risco de racionamento ou desabastecimento público de água para a cidade também se recomenda que o uso e ocupação da bacia seja mais bem orientado e fiscalizado. A maior parte da bacia está em uma Área de Proteção Ambiental (APA) que é uma categoria de unidade de conservação, porém ela é muito pouco restritiva quanto ao uso do solo, aliado a isso, há um aumento crescente de loteamentos na bacia, o que pode levar a um aumento populacional e consequentemente a uma maior demanda por água.

Recomenda-se que o governo municipal controle melhor o micro parcelamento da área rural da bacia, já que são as áreas de recarga de aquíferos e mananciais de uma forma geral. O comprometimento desses locais também pode fazer com que a disponibilidade hídrica 
diminua, principalmente nos períodos de estiagem, que com este estudo apontou, são os mais críticos para garantir uma maior segurança hídrica aos usuários.

Haverá necessidade também de campanhas que fomentem o uso racional da água na cidade, assim como de evitar desperdícios e a redução de perdas na distribuição de água por parte da concessionária responsável.

Atualmente se estuda a possibilidade de captar de outros mananciais, como do reservatório da UHE Luís Eduardo Magalhães que margeia a cidade, porém a qualidade da água desse reservatório demandará uma série de adaptações no tratamento da água, o que torna a bacia do Taquaruçu ainda o principal manancial de abastecimento de água para a cidade de Palmas - TO.

\section{Agradecimentos}

O presente trabalho foi realizado com apoio da Fundação de Amparo à Pesquisa do Estado do Tocantins (FAPT) por meio do Edital FAPT 16/2012, Programa de Pesquisa em Recursos Hídricos FAPT/SEMADES.

\section{Referências}

AZEVEDO, L. G.; BALTAR, A M.; RÊGO, M.; PORTO, L. R. Sistemas de Suporte à Decisão para a Outorga de Direitos de Uso da Água no Brasil. Brasília: Banco Mundial (Série Água Brasil, 2). 2003.

BARROS, D. J. et al. Análise da Ocorrência de Metais em Águas Superficiais e Produção de Sedimentos na Rede Hidrográfica do Ribeirão Taquaruçu Grande, Palmas - TO. In: SIMPÓSIO BRASILEIRO DE RECURSOS HÍDRICOS, 19., 2011, Maceió. Anais...Maceió: ABRH, 2011.

BRASIL. Lei no 9.433, de 8 de janeiro de 1997. Institui a Política Nacional de Recursos Hídricos e cria o Sistema Nacional de Gerenciamento de Recursos Hídricos. Diário Oficial [da] República Federativa do Brasil, Brasília, DF, n. 6, 9 jan. 1997. p. 470-474.

CASTRO, K.B. Avaliação do Modelo SWAT na simulação da vazão em bacia agrícola do cerrado intensamente monitorada. 2013. 141 f. Dissertação (Mestrado em Geociências) - Instituto de Geociências, Universidade de Brasília, Brasília, 2013.

COLLISCHONN, B.; LOPES, A.V. Sistema de Controle de Balanço Hídrico para apoio a outorga na bacia do São Francisco. In: ENCONTRO NACIONAL DE HIDROINFORMÁTICA, 1., 2008, Fortaleza. Anais eletrônicos... Fortaleza: UNIFOR, 2008. Disponível em: <http:www.ana.gov.br>. Acesso em: jun. 2015.

COLLISCHONN, B.; LOPES, A. V. Sistema de Apoio à Decisão para análise de outorga na bacia do rio Paraná. In: SIMPÓSIO BRASILEIRO DE RECURSOS HÍDRICOS, 18., 2009, Campo Grande. Anais...Campo Grande: ABRH, 2009.

FARIAS, T.Q. Outorga de direito de uso dos recursos hídricos no ordenamento jurídico brasileiro. Revista Direito e Liberdade, v. 8, n. 1, p. 1-11, 2008. 
KAYSER, R. H. B. Sistema de suporte à decisão para gerenciamento de recursos hídricos integrado a um SIG: desenvolvimento e aplicação na Bacia do Rio dos Sinos. 2011. 123 f. Monografia (Graduação em Engenharia Ambiental) - Instituto de Pesquisas Hidráulicas, Universidade Federal do Rio Grande do Sul, Porto Alegre, 2011.

MEDEIROS, W. Manual de Aplicação do modelo SAD-IPH na bacia do rio Capim no Estado do Pará. Diretoria de Recursos Hídricos, SEMA. 2014. Disponível em: <http://willmedeiros.blogspot.com.br/2014/03/manual-deaplicacao-do-modelo-sad-iph.html>. Acesso em: ago. 2015.

MEIRA NETO, A.A.; FONTES, A.S.; MEDEIROS, Y.D.P. Aplicabilidade do modelo SWAT a um sistema hidrológico complexo de clima semi-árido. In: SIMPÓSIO BRASILEIRO DE RECURSOS HÍDRICOS, 19., 2011, Maceió. Anais...Maceió: ABRH, 2011. 1 CD-ROM.

PALMAS. Secretaria Municipal de Assuntos Jurídicos. Plano Municipal de Saneamento Básico de Palmas: Volume II: Água e Esgoto. 2014. Disponível em: http://www.palmas.to.gov.br/servicos/pmsb-plano-municipalde-saneamento-basico/179/. Acesso em: jan. 2015.

PEREIRÁ PESSOA, M.M.E. Integração de Modelos Hidrológicos e Sistemas de Informação Geográfica na análise de processos de Outorga Quantitativa de uso da água: Aplicação na Bacia do Rio dos Sinos - RS. 2010. $91 \mathrm{f}$. Dissertação (Mestrado em Recursos Hídricos e Saneamento Ambiental) - Instituto de Pesquisas Hidráulicas, Universidade Federal do Rio Grande do Sul, Porto Alegre, 2010.

PORTO, R. L. L.; AZEVEDO, L. G. T. Sistemas de suporte a decisões de recursos hídricos. In: Porto, R. L. L. Técnicas quantitativas para o gerenciamento de recursos hídricos. Porto Alegre: UFRGS/ABRH, 1997. cap. 2, p.43-95.

RODRIGUES, R.B. SSD RB - Sistema de Suporte a Decisão proposto para a Gestão Quali-Quantitativa dos processos de outorga e cobrança pelo uso da água. 2005. 155f. Tese (Doutorado em Engenharia Hidráulica e Sanitária) - Escola Politécnica da Universidade de São Paulo, São Paulo, 2005.

RIO GRANDE DO SUL (Estado). Secretaria de Meio Ambiente. Departamento de Recursos Hídricos. Processo de Planejamento da Bacia Hidrográfica do rio Ibicuí - Fases A e B: Definição do processo de enquadramento. Porto Alegre: SEMA, 2011.

SILVA, M.M.A.P. de M. Modelagem da qualidade da água na bacia do rio Piracicaba - MG. 2014. $164 f$. Dissertação (Mestrado) - Programa de Pós-graduação em Análise e Modelagem de Sistemas Ambientais, Universidade Federal de Minas Gerais, Belo Horizonte, 2014.

SILVA, M.M.A.P.M.; FARIA, S.D.; MOURA, P.M. Modelagem da qualidade da água na bacia hidrográfica do Rio Piracicaba (MG). Eng Sanit Ambient, v.22, n.1, p. 133-143, jan-fev 2017.

SILVA NETO, A. R. S. N. Cenários de Abastecimento Futuro de Palmas com base na simulação da disponibilidade hídrica do Ribeirão Taquaruçu Grande. 2011. 91f. Dissertação (Mestrado em Recursos Hídricos e Saneamento Ambiental) - Instituto de Pesquisas Hidráulicas, Universidade Federal do Rio Grande do Sul, Porto Alegre, 2011.

VON SPERLING, M. Introdução à Qualidade das Águas e ao Tratamento dos Esgotos Vol.1. Belo Horizonte, UFMG, 1995.

VEIGA, A. M. Calibração do modelo hidrossedimentológico SWAT na bacia hidrográfica do Córrego Samambaia, Goiânia - GO. 2014. 125 p. Dissertação (Mestrado em Engenharia do Meio Ambiente) - Escola de Engenharia Civil, Universidade Federal de Goiás, Goiânia, 2014. Disponível em: https://repositorio.bc.ufg.br/tede/bitstream/tede/3497/5/Disserta\%C3\%A7\%C3\%A30\%20\%20Aldrei\%20Marucci\%20Veiga\%20-\%202014.pdf. Acesso em: 18 jun. 2016. 